\title{
Emphysema in young adult survivors of moderate-to-severe bronchopulmonary
} dysplasia

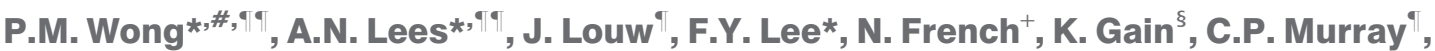 \\ A. Wilson*, ${ }^{*}$ and D.C. Chambers*,\#,f
}

ABSTRACT: Improved survival following extreme preterm birth complicated by bronchopulmonary dysplasia (BPD) is resulting in an increasing number of affected infants surviving to adulthood. The aim of the present pilot study was to describe the functional and structural pulmonary sequelae of moderate and severe BPD in a population of adult survivors.

All babies were cared for at one institution (King Edward Memorial Hospital, Subiaco, Australia). Subjects born between 1980 and 1987 with birthweight $<1,500 \mathrm{~g}$ and requiring supplementary oxygen at 36 weeks post-menstrual age were identified from a complete neonatal database and recruited prospectively. Local physicians were concurrently asked to refer suitable patients. Demographics, respiratory symptoms and examination results, pulmonary function tests and computed tomography images were acquired.

In total, 21 subjects were studied. Of these, 12 were female, the median (range) age was 19 (17$33)$ yrs and $15(71 \%)$ had persistent respiratory symptoms. The median (range) forced expiratory volume in one second (FEV 1$)$ z-score was $-0.77(-8.20-1.37)$, the forced expiratory flow at $25-75 \%$ of forced vital capacity was $-1.81(-6.00-0.75)$ and the diffusing capacity of the lung for carbon monoxide was $-5.04(-13.17--1.24)$. Computed tomography was carried out on 19 subjects and all had abnormal findings, with emphysema being the most common, present in $84 \%$ of subjects. The extent of radiological emphysema was inversely related to the FEV1 z-score.

Young adult survivors of moderate and severe bronchopulmonary dysplasia may be left with residual functional and characteristic structural pulmonary abnormalities, most notably emphysema.

KEYWORDS: Adult, bronchopulmonary dysplasia, computed tomography, emphysema, lung function, preterm birth

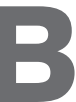

ronchopulmonary dysplasia (BPD; formerly termed chronic lung disease of infancy), defined as continued dependence on supplementary oxygen for $\geqslant 28$ days post-partum [1], is the most common and the most significant long-term pulmonary complication of preterm birth [2]. The incidence of live, spontaneous preterm birth is increasing [3] and, concomitantly, post-partum survival of preterm babies has increased over the last $30 \mathrm{yrs}$ due to advances in neonatal care [4]. BPD now affects as many as $35 \%$ of very low birthweight (VLBW) infants $(<1,500 \mathrm{~g})$ [5]. Many of the first infants to benefit from these improvements in neonatal care are now reaching adulthood.

There is good evidence that BPD is associated with both increased respiratory symptoms and reduced lung function during childhood [6-9]. Lung function abnormalities commonly described include both gas trapping and reduced forced expiratory flow (FEF) rates. While some investigators have found that lung function improves during childhood [10], most have found persistent abnormalities [11-13]. Few studies have carefully examined lung structural abnormalities in older children, but it would appear that most have residual structural pulmonary abnormalities and that these abnormalities are associated with impaired pulmonary function [14].

There is very little data concerning the pulmonary sequelae of BPD as survivors enter adulthood. Since Northway et al. [15] described airway obstruction, hyperreactivity and hyperinflation in some of the first adult survivors of BPD, other investigators have found similar lung function abnormalities in late childhood, adolescence and early adulthood [16-19]. Few studies
AFFILIATIONS

*Advanced Lung Disease Program, Depts of "Diagnostic Imaging, ${ }^{\S}$ Respiratory Medicine, Royal Perth Hospital, Perth

\#Lung Institute of Western Australia, Sir Charles Gairdner Hospital, Nedlands,

+Neonatal Critical Care Unit, King Edward Memorial Hospital, Subiaco, WA,

${ }^{f}$ Thoracic Dept, The Prince Charles Hospital, Brisbane, QLD, Australia.

" Both authors contributed equally to this article.

CORRESPONDENCE

D.C. Chambers

Thoracic Dept

Level 2 Administration Building

The Prince Charles Hospital

Brisbane

Queensland 4032

Australia

Fax: 61731394510

E-mail: Daniel_Chambers@

health.qld.gov.au

Received:

September 262007

Accepted after revision:

March 182008

STATEMENT OF INTERES

None declared. 
have assessed lung structure in adult survivors of preterm birth [14, 20, 21], and none have examined lung function or computed tomography (CT) exclusively in adult survivors of more severe BPD.

The aim of the present observational pilot study was to make an initial assessment of the functional and structural consequences of moderate and severe BPD during adult life, in order to guide future larger studies. The current authors hypothesised that functional and structural lung abnormalities would persist into adulthood and that abnormalities in lung structure would correlate with abnormalities in lung function.

\section{MATERIALS AND METHODS \\ Study population}

Western Australia (population 2,100,000) is the largest state by area in Australia, covering the western third of the continent. Its capital, Perth, is the most isolated large city in the world. All infants with BPD in Western Australia are cared for at a single institution (King Edward Memorial Hospital) in Subiaco, Perth, with uniform diagnosis and treatment protocols. Surfactant and post-natal corticosteroid treatments were not included in management protocols until 1990 and 1992, respectively. A prospective BPD database has been maintained with complete records since 1980. At the time the database was established, the diagnosis was based on the pre-National Institutes of Health (NIH) consensus definition of birthweight, $<1,500 \mathrm{~g}$, and continued dependence on supplementary oxygen after 36 weeks post-menstrual age; hence, the subjects included would today all meet the NIH consensus criteria for moderate or severe BPD [1]. Recent contact details were obtained from contemporary hospital databases for subjects born between 1980 and 1987, inclusive, aged 18-26 yrs at the time of the study. These details were cross-checked with the Registry for Births, Deaths and Marriages before a letter of invitation to participate in the study was posted. A second letter was sent if no response had been received within 3 weeks. Concurrently, all adult respiratory physicians in Western Australia were contacted by mail, and encouraged to refer subjects who met the study inclusion criteria.

Pregnant subjects were excluded until after delivery, and subjects with neurosensory impairments severe enough to impede the acquisition of study data were also excluded.

\section{Methods}

After written informed consent was obtained, participants completed the symptom questionnaire prepared for the Respiratory Disease Committee of the International Union Against Tuberculosis and Lung Disease. A medical history was obtained, covering past admissions, diagnoses, medications, allergies, smoking, drug and family history. Subjects were also questioned regarding their educational and employment histories, marital and relationship status and use of social services.

A respiratory physical examination was performed, focusing on height, weight, respiratory rate, pulse, blood pressure and oxygen saturation after $5 \mathrm{~min}$ of rest. Chest deformity and the presence of wheeze and crepitations were assessed.

Comprehensive pulmonary function tests (FEF measurements, lung volumes by helium dilution and diffusing capacity of the lung for carbon monoxide $(D \mathrm{~L}, \mathrm{CO})$ ) were then performed by a senior respiratory technician, following American Thoracic Society guidelines. Respiratory technicians were blinded to clinical details and inhaled $\beta_{2}$-agonists were withheld on the day of the tests. The DL,CO was haemoglobin-corrected if there was a history of anaemia. Exercise testing was not performed. The z-scores for the forced expiratory volume in one second (FEV1) and FEF at 25-75\% of forced vital capacity (FVC; FEF25$75 \%$ ) were calculated using the equations of KNUDSON et al. [22], the $\mathrm{z}$-scores for lung volumes were calculated according to CRAPO et al. [23], while the z-scores for DL,CO were calculated using the equations of COTES et al. [24]. Values of $\mathrm{z}>1.96$ or $<-1.96$ defined an abnormal test result.

CT images were acquired in both the inspiratory and expiratory phases. Thin-section selective CT was performed using a 64-slice CT machine (Philips Brilliance $64^{\mathrm{TM}}$; Philips Medical Systems, Eindhoven, the Netherlands), with the production of $0.63-\mathrm{mm}$ images at $10-\mathrm{mm}$ intervals and three expiratory images performed at evenly spaced intervals above, at and below the tracheal carina. This corresponded to a maximum radiation dose of $1 \mathrm{mSv}$. The $\mathrm{CT}$ images were acquired on the same day as pulmonary function tests were performed. The CT data was viewed on high resolution monitors (Dome ${ }^{\mathrm{TM}}$; Planar Systems, Beaverton, OR, USA) C3i $1,536 \times 2,048$ pixel grayscale flat panel) and analysed with commercially available soft copy reporting tools (Agfa $\mathrm{IMPAX}^{\mathrm{TM}}$; Agfa Healthcare, Mortsel, Belgium). The scans were evaluated in consensus by two subspecialist thoracic radiologists who were blinded to the patient's clinical details.

The images were evaluated for the presence and extent of gas trapping, bronchial dilation, bronchial wall thickening, architectural distortion and emphysema. Emphysema was defined according to AQUINO et al. [14], as "areas of very low attenuation containing no perceptible parenchymal anatomy. This pattern was distinguished from areas of decreased density in which parenchymal structures (e.g. lobular anatomy) could still be identified". The voxel index, the proportion (percentage) of lung voxels of low density below a threshold of -950 Hounsfield units (HU), provides a quantitative assessment of emphysema severity that has been validated in crosssectional pathological $[25,26]$ and longitudinal clinical studies [27]. The voxel index was derived utilising the Philips 64 Brilliance Extended Workspace Lung ${ }^{\text {TM }}$ (Philips Medical Systems) assessment package (lung emphysema), set at a maximum threshold of $-950 \mathrm{HU}$.

Follow-up of significant abnormalities was offered on an ongoing basis via the adult BPD clinic at the Royal Perth Hospital (Perth, Australia). The study was reviewed and approved by both the Royal Perth Hospital and King Edward Memorial Hospital Human Research and Ethics Committees and the Western Australian Radiation Protection Council.

\section{Analysis}

Data are presented as median and range. The Kruskal-Wallis one-way ANOVA by ranks test was used to compare the demographic and perinatal data by participation. Linear regression was used to compare continuous variables and the coefficient of determination was calculated. A value of $\mathrm{p}<0.05$ was taken to indicate statistical significance. 
TABLE 1 Demographics and perinatal data for study participants, those who declined and those who were not contactable

\begin{tabular}{lccc} 
& Participants & Declined to participate & Not contactable \\
\hline Subjects $\mathbf{n}$ & 21 & 28 & 89 \\
Age yrs & $19(17-33)$ & $21(19-26)$ & $21(18-26)$ \\
Females n (\%) & $12(57)$ & $10(36)$ & $43(48)$ \\
Gestation weeks & $27(24-30)$ & $28(24-33)$ & $27(23-32)$ \\
Birthweight g & $895(635-1355)$ & $980(565-1465)$ & 0.03 \\
Mechanical ventilation days & $38(9-135)$ & $34(0-90)$ & 0.21 \\
Supplementary oxygen days & $93(50-374)$ & $77(35-196)$ & $385(0-86)$ \\
\hline
\end{tabular}

Data are presented as median (range), unless otherwise stated.

\section{RESULTS}

In Western Australia, 138 babies were born between 1980 and 1987 weighing $<1,500 \mathrm{~g}$ and requiring supplementary oxygen beyond 36 weeks post-menstrual age. Of these, five had died and $47(35 \%$ of 133$)$ were contactable and, of these, $20(42.6 \%)$ agreed to participate. Due to sensorineural impairment secondary to cerebral palsy, one subject was excluded. Respiratory physicians referred two additional subjects: a 17yr-old male and a 33-yr-old female. Therefore, in total, 12 females and nine males, with median (range) age 19 (1733) yrs, including one set of triplets, were studied. Spirometry was unattainable in one subject and diffusing capacity in two.

For the study group, the median (range) gestational age at birth was 27 (24-30) weeks and birthweight was 895 (635$1,355) \mathrm{g}$. Supplementary oxygen was required for $93(50$ $374)$ days and mechanical ventilation for 38 (9-135) days. The post-menstrual age on the last day of supplementary oxygen was 39.1 (36.1-78.4) weeks. Although the group studied were slightly younger, there were no statistically significant differences in any perinatal variables between those studied, those who declined or were excluded and those who were not contactable (table 1).

Of the participants, two had a history of asthma: one was taking inhaled salbutamol, fluticasone, salmeterol and tiotropium and the other required salbutamol and fluticasone. In the remainder $(n=19)$, there was no history of a current respiratory diagnosis; however, one patient was taking over-the-counter inhaled salbutamol for dyspnoea. Additionally, two patients had a past history of resolved childhood asthma, three patients had been hospitalised for pneumonia beyond early childhood, at age 16, 17 and $32 \mathrm{yrs}$, and only one subject had received follow-up for BPD beyond childhood.

Although the majority of the subjects had no past smoking history, two subjects were current smokers, each with a total history of 1 pack-yr. The smoking patients did not have a comorbid respiratory diagnosis and had milder disease according to $\mathrm{CT}$ and lung function testing. Some level of passive smoke exposure was present in $50 \%$ of the subjects. A personal history of atopy was present in $38 \%$, and $48 \%$ had a family history of atopy. Persistent respiratory symptoms, including wheeze, cough, and dyspnoea, were reported by $71 \%$ of subjects (table 2 ).

Physical examination findings were abnormal in five patients. The median (range) height was 165 (150-187) $\mathrm{cm}$ and weight was $63(36-99) \mathrm{kg}$. Hypertension was present in two patients, who had blood pressures of 140/90 and 130/100 mmHg. Chest deformity was evident in three patients: one had pectus excavatum, one had Harrison's sulcus and one subject had both signs. Wheeze was auscultated in one patient and reduced air entry in two patients. There were no other abnormal auscultatory findings. The oxygen saturation was 99 (95-100)\% while breathing room air.

The CT findings were abnormal in all 19 consenting subjects; two subjects did not consent. The most prominent structural finding was emphysema, present in $16(84 \%)$ out of 19 subjects (figs 1-3). While all types of emphysema were evident, centrilobular emphysema was most common, present in 14 $(74 \%)$ of the 19 subjects. Of these subjects, four demonstrated other emphysema types in addition to centrilobular: two panacinar, one bullous, and one paraseptal. The remaining

TABLE 2 Selected results of the International Union Against Tuberculosis and Lung Disease respiratory symptoms questionnaire for 21 participants

Question

Participants answering "Yes" \%

Have you, at any time in the last 12 months, been woken at night by an attack of coughing?

Have you, at any time in the last 12 months, had wheezing or whistling in your chest?

Have you, at any time in the last 12 months, had an attack of shortness of breath that came on during the day 


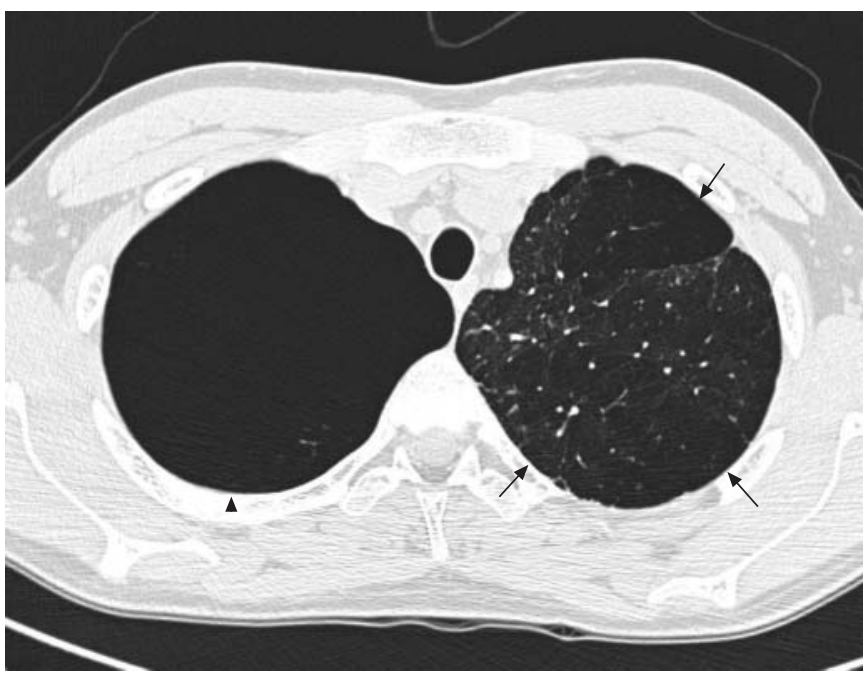

FIGURE 1. Thin-section computed tomography scan of a 20 -yr-old nonsmoking male, born weighing $1,355 \mathrm{~g}$ at 28 weeks gestation, dependent upon supplementary oxygen until 321 days post-partum. The forced expiratory volume in one second z-score was -8.20. There was severe emphysema (arrows) and almost complete replacement of the right upper lobe with a large bulla (arrowhead; voxel index 68\%).

two subjects had exclusively panacinar emphysema. The median (range) voxel index was $13.1(2.5-68) \%$. In all individuals with significant emphysema, $\alpha_{1}$-antitrypsin deficiency was excluded.

Other CT features detected included architectural distortion in eight $(42.1 \%)$ subjects, bronchial wall thickening in eight $(42.1 \%)$ subjects, gas trapping in seven $(36.8 \%)$ subjects and bronchiectasis in one $(5.2 \%)$ subject. No subjects displayed a reduced broncho-arterial ratio.

Lung function data are presented in figure 4. Only three subjects had normal lung function. An abnormal FEV1 was seen in five
(25\%) out of 20 subjects, and all of these had an abnormal FEF25-75\%. An additional four subjects had an abnormal FEF25-75\% despite having a normal FEV1. A reduced DL,CO was measured in $16(84 \%)$ out of 19 subjects, and while most had associated airflow limitation, seven out of the 16 subjects had no spirometric evidence of airflow limitation. A raised residual volume (RV) was found in six (28\%) out of 21 subjects, while only one subject had an abnormal total lung capacity.

There was a significant correlation between radiological emphysema severity (voxel index) and FEV1, with worse radiological emphysema predicting lower FEV1 $\left(R^{2}=0.50\right.$, $p=0.001$; fig. 5), lower FEF25-75\% $\left(R^{2}=0.41, p=0.003\right)$ and higher $R V\left(R^{2}=0.44, p=0.002\right)$. However, there was no significant correlation between $D \mathrm{~L}, \mathrm{CO}$ and radiological emphysema severity $\left(R^{2}=0.08, p=0.26\right.$; fig. 6$)$.

Outcomes were also compared with perinatal data, but overall there was no perinatal factor that strongly predicted adverse adult outcome. There was a significant negative correlation between the duration of supplementary oxygen administration and adult FEV1 $\left(\mathrm{R}^{2}=0.28, \mathrm{p}=0.02\right)$; however, there was no correlation between the duration of supplementary oxygen administration and radiological emphysema severity $\left(R^{2}=0.02\right.$, $\mathrm{p}=0.58)$. Adult FEV1 was not associated with either birthweight $\left(R^{2}=0.12\right)$ or gestational age $\left(R^{2}=0.07\right)$. Radiological emphysema severity was also not associated with gestational age $\left(R^{2}=0.14\right)$. Birthweight did predict radiological emphysema severity, but not as expected: increasing birthweight predicted worse emphysema $\left(\mathrm{R}^{2}=0.24, \mathrm{p}=0.038\right)$. The results were not different if the two individuals with a cigarettesmoking history were removed from the analysis.

\section{DISCUSSION}

In the present observational pilot study, emphysema was identified as the principal radiological abnormality in a cohort of adult survivors of moderate and severe BPD who had not been treated with surfactant. Radiological emphysema correlated with abnormal pulmonary function, including reduced FEF rates and
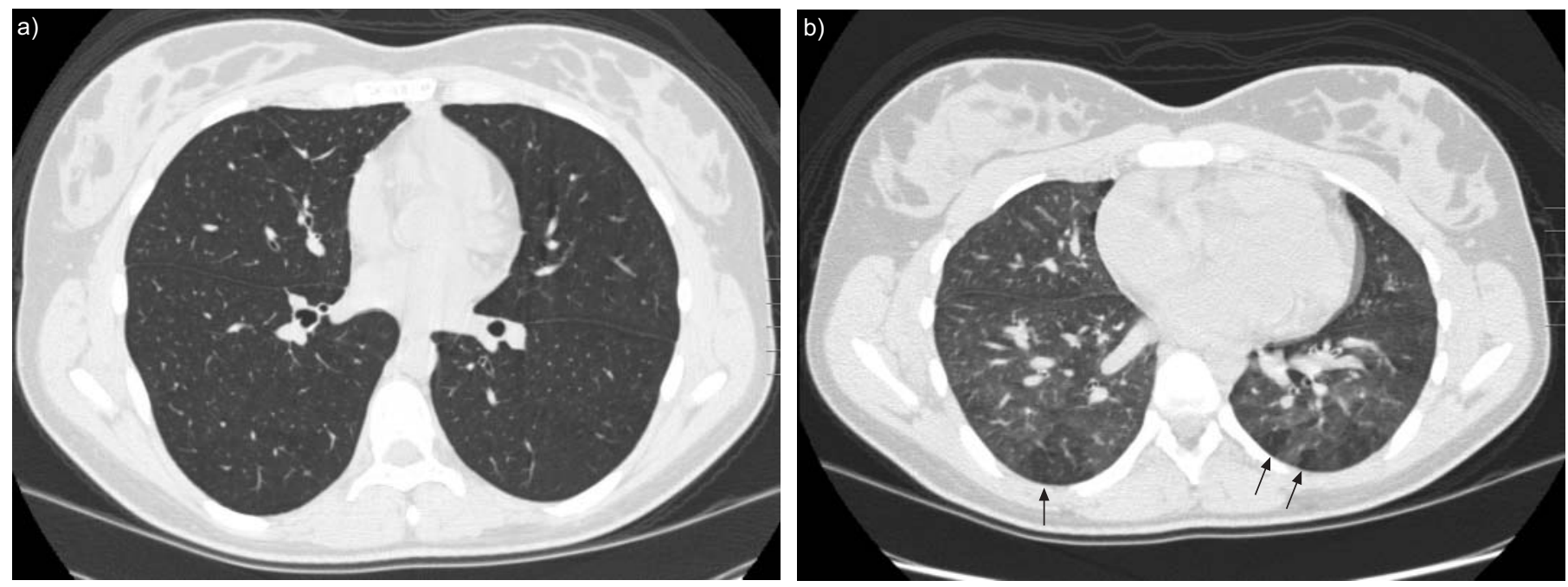

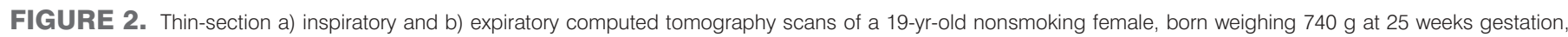

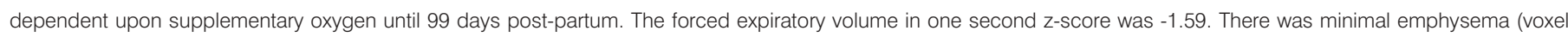
index $3.3 \%$ ) and moderate multilobular air-trapping seen on the expiratory film (arrows). 

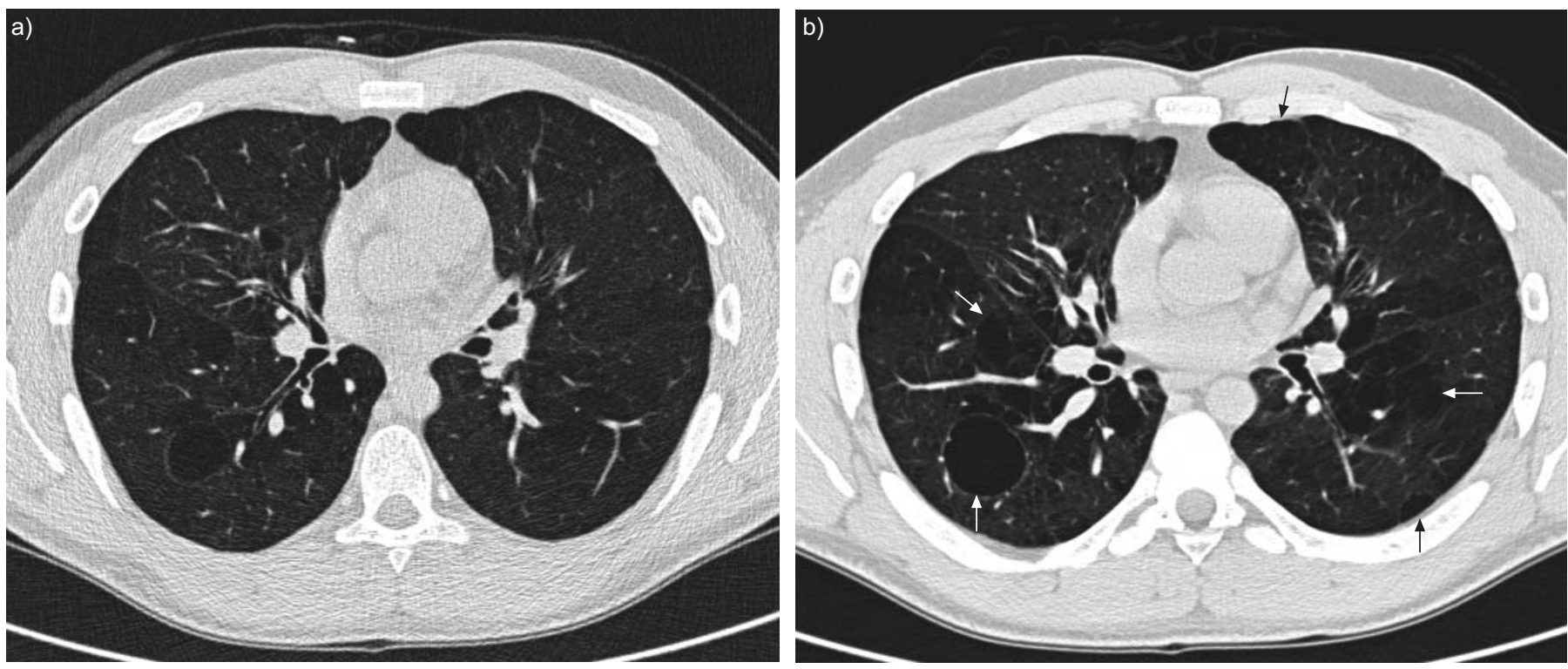

FIGURE 3. Thin-section a) inspiratory and b) expiratory computed tomography scans of a 25-yr-old nonsmoking male, born weighing 1,100 $\mathrm{g}$ at $29 \mathrm{meeks}$ gestation, dependent upon supplementary oxygen until 60 days post-partum. The forced expiratory volume in one second z-score was -4.75 . There was moderate-to-severe emphysema (arrows; voxel index 46.7\%).

gas trapping, irrespective of smoking status. All 19 subjects who underwent CT had abnormal radiological findings, and $16(84 \%)$ had areas of emphysema. A similar number of subjects had an abnormal DL,CO. While the total burden of adult disease in survivors of BPD will need to be determined from larger studies, the present findings carry potentially significant implications for these individuals and the physicians and healthcare systems that care for them as they move into later adulthood.

The lung function abnormalities in the current adult cohort closely reflect previous studies, summarised in table 3 . In the 1990 study by NoRTHWAy et al. [15] of 26 adolescent and young

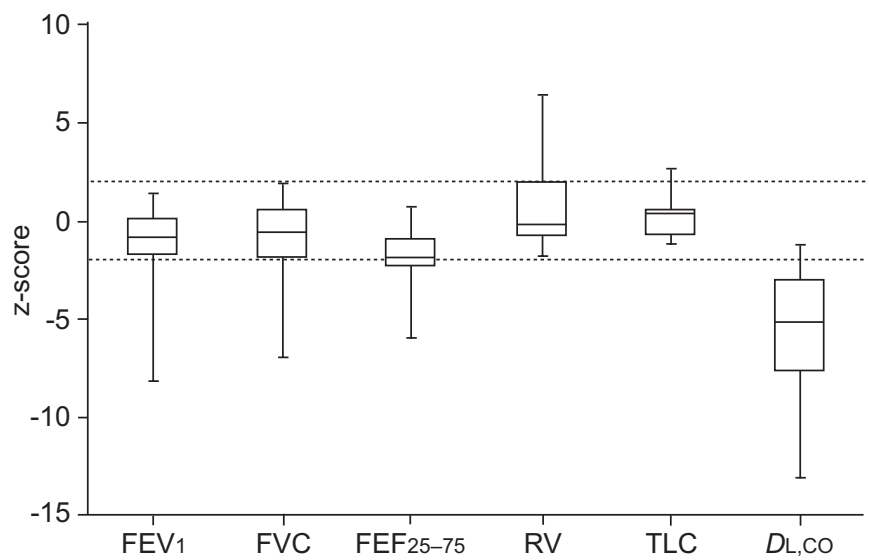

FIGURE 4. Lung function z-score results for the 21 study participants. Boxand-whisker plots present the first, second and third quartiles (box) and the minimum and maximum values (whiskers). FEV1: forced expiratory volume in one second; FVC: forced vital capacity; FEF25-75\%: forced expiratory flow at 25-75\% of FVC; RV: residual volume; TLC: total lung capacity; DL,CO: diffusing capacity of the lung for carbon monoxide; $\cdots \cdots \cdot \mathrm{z}=1.96$ and $z=-1.96$ (upper and lower, respectively) adult survivors (mean age 18.3 yrs), 25\% of subjects had significant pulmonary symptoms (a greater number of wheezing episodes, pneumonias and use of respiratory medications) compared with age-matched controls born prematurely with no need for mechanical ventilation and a group born at term. Of the 25 subjects, $17(68 \%)$ had airway obstruction. While airway obstruction was classified as mild or moderate in most subjects, $24 \%$ of subjects had fixed airway obstruction [15]. In a Norwegian population-based study, HALVORSEN et al. [17] studied 46 ex-preterm adolescents and young adults (mean age 17.7 yrs), 12 of whom had moderate or severe BPD. For that group of BPD subjects, the pulmonary function tests indicated an obstructive picture and bronchial hyperreactivity tended to increase with worsening BPD [17]. In a hospital-based Dutch study of ex-preterm 19-yr-olds that included lung function

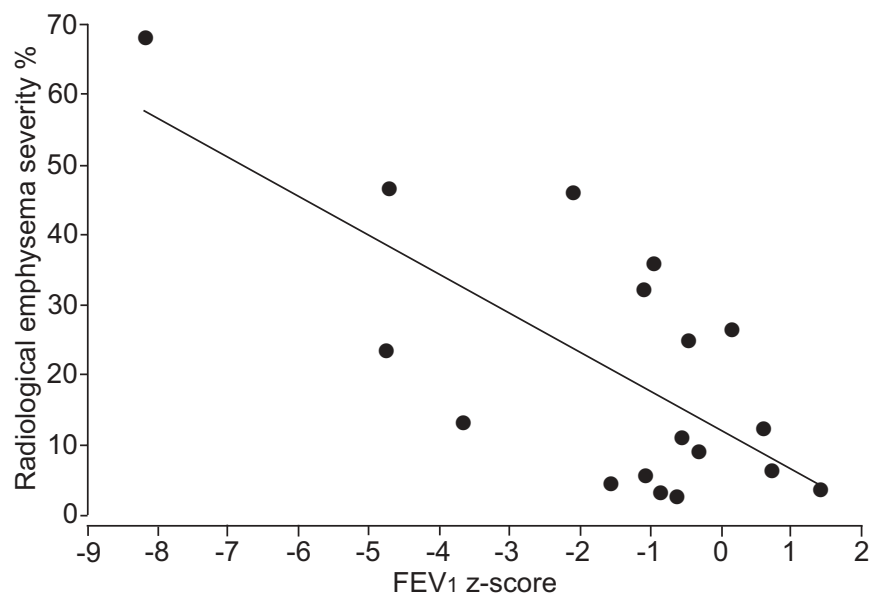

FIGURE 5. Forced expiratory volume in one second (FEV1) z-score versus radiological emphysema severity as measured by the voxel index percentage [26] $R^{2}=0.5016$ 


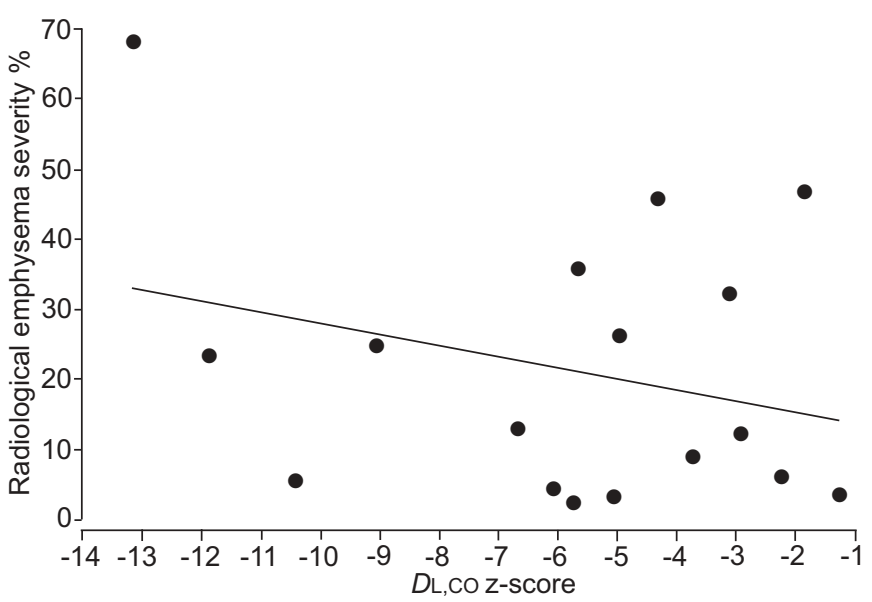

FIGURE 6. Diffusing capacity of the lung for carbon monoxide $(D\llcorner, C O)$ z-score versus radiological emphysema severity as measured by the voxel index percentage [26]. $R^{2}=0.0848$.

measurements in nine patients with BPD (not further defined as mild/moderate or severe), VRIJLANDT et al. [18] also showed that lung function was obstructive in nature; however, lung function was similar between the BPD and preterm non-BPD group. In a 2003 study by DOYLE et al. [16] of 20-yr-old survivors of VLBW $(<1,000 \mathrm{~g})$, lung function data for 18 patients with BPD was included. While $20.5 \%$ of the entire group had evidence of airflow limitation (FEV1/FVC ratio $<75 \%$ ), the prevalence of airflow limitation was not higher in the patients who met the criteria for BPD. In a 2006 study by DoYLE et al. [19] of 147 VLBW babies, 33 patients of mean age 19.4 yrs met the criteria for moderate or severe BPD. Lung function was significantly lower for BPD versus non-BPD subjects and was obstructive with FEV $1 / \mathrm{FVC}<75 \%$ in $42.4 \%$ of patients and FEV $1<75 \%$ predicted in $30.3 \%$ of patients. In accordance with the present study, neither birthweight nor gestational age predicted adult pulmonary function [19]. When lung function was compared between 8 and 18 yrs of age, the decline in FEV1/FVC was significantly greater for BPD versus non-BPD cases ( -5.6 versus $-3.4 \% ; \mathrm{p}=0.04)$ [19]. Taken together, the current study and existing published literature strongly suggest that adult survivors of BPD have residual pulmonary function abnormalities consistent with obstructive lung disease.

Only two previous studies have assessed DL,CO in adult survivors of BPD. HowLING et al. [21] included a heterogeneous group of five subjects with birthweights ranging 990-2,268 $\mathrm{g}$ and gestations 28-35 weeks, all of whom had a normal $D \mathrm{~L}, \mathrm{CO}$, while in the study by VRIJLANDT et al. [18], the mean DL,CO for the eight subjects with BPD was $91.4 \%$. In contrast, 16 (84\%) of the 19 present tested subjects had a low DL,CO. The median (range) z-score was -5.04 (-13.17- -1.24), possibly reflecting more severe perinatal disease in the current study cohort. Surprisingly, the DL,CO correlated poorly with the severity of emphysema as assessed by voxel index (fig. 6), and only seven of these 16 subjects had accompanying airflow limitation. Since $\mathrm{BPD}$ is characterised by arrested airspace and pulmonary vascular development [28], the possibility of established or emerging pulmonary vascular disease is of concern in this group and is currently being evaluated [28, 29].

All of the subjects in the present study had abnormal lung structure as assessed by CT, and $84 \%$ had areas of emphysema.

TABLE 3 Lung function data for adult survivors of bronchopulmonary dysplasia (BPD)

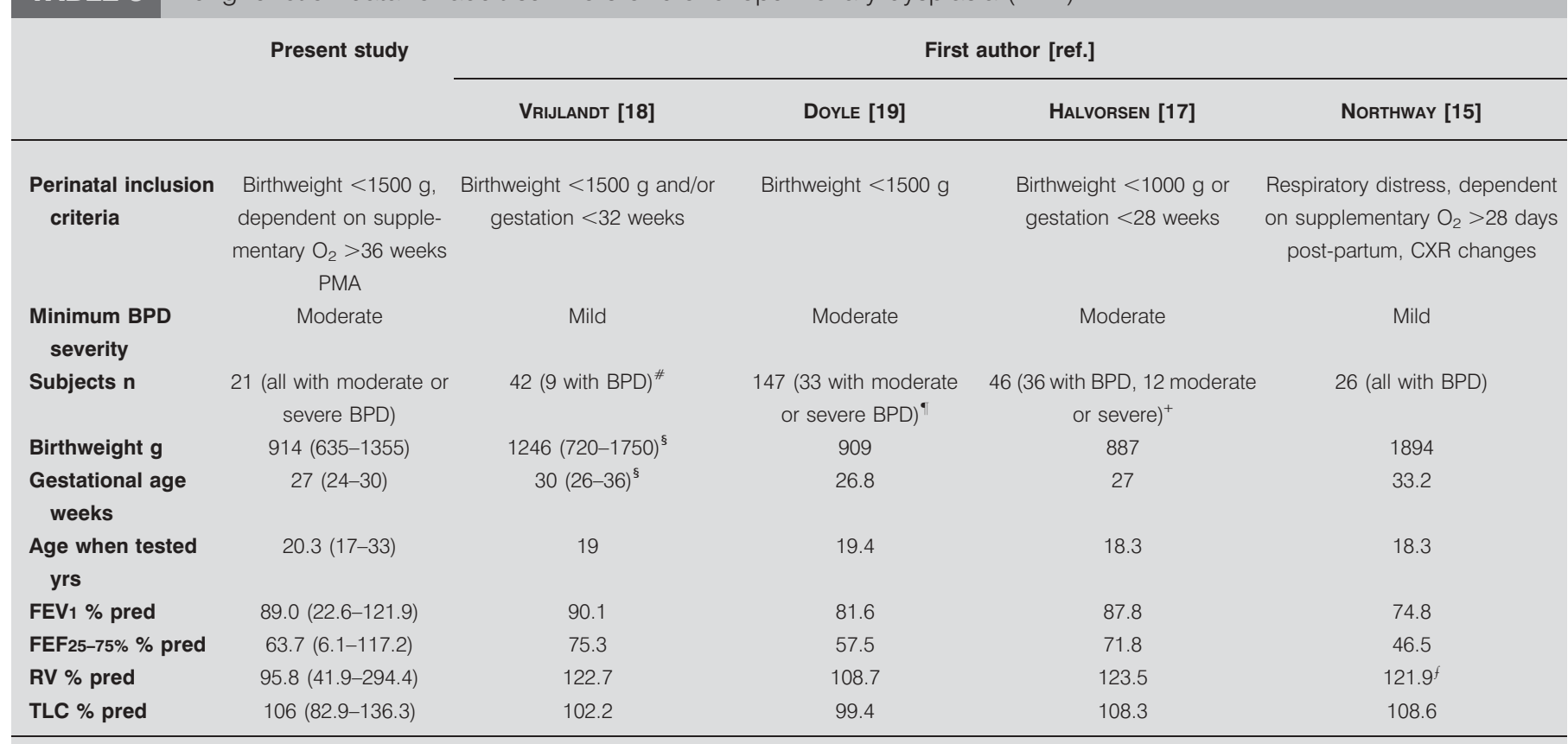

Data are presented as mean or median (range), unless otherwise specified. FEV1: forced expiratory volume in one second; \% pred: \% predicted; FEF25-75\%: forced expiratory flow at $25-75 \%$ of forced vital capacity; RV: residual volume; TLC: total lung capacity; PMA: post-menstrual age; CXR: chest radiograph. ${ }^{\#}$ : data for the entire

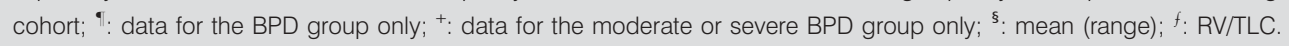


There is limited information regarding lung structural abnormalities in adult survivors of BPD available from the published literature, since only three previous studies have included CT imaging $[14,20,21]$. The only study to exclusively examine adults with a history of BPD was a retrospective study of hard-copy CT images from five subjects (aged 20-26 yrs) whose birthweights (990-2,268 g) and gestations (28-35 weeks) suggested heterogeneous aetiologies for neonatal respiratory distress [21]. This study described widespread reduced lung attenuation, bronchial wall thickening, decreased bronchus-toarterial diameter ratios, linear opacities and bullae. Reduced lung attenuation was attributed to gas trapping [21]. In a 1999 study, AQUiNo et al. [14] prospectively studied hard-copy inspiratory and expiratory CT films from 26 children with median (range) age 10 (5-18) yrs. Of these, 20 (77\%) had areas of reduced lung attenuation involving $5-70 \%$ of the lung; however, only one case was attributed to emphysema. Evidence of gas trapping was seen on expiratory images from $24(92 \%)$ subjects [14]. In a more recent and larger Norwegian study using soft-copy inspiratory and expiratory CT images from ex-preterm children and adults (two birth cohorts with mean ages 10 and $18 \mathrm{yrs}$ ), 87.5\% had abnormal radiological findings, particularly linear and triangular opacities, gas trapping (in $26.4 \%$ of cases) and mosaic perfusion. No patients had radiological emphysema [20].

Emphysema has long been recognised pathologically and radiologically in infants and young children with BPD [30] and is likely to be the result of arrested or disturbed alveolar and vascular development [28]. Despite this, the present finding of predominant emphysema in adult survivors of moderate and severe BPD is at odds with the current published literature. This may well reflect the more severe perinatal disease in the current cohort, since other studies have included subjects without BPD or with mild BPD [14, 20,21], children or subjects who may have received surfactant or glucocorticoids [14, 20]. Additionally, the use of modern CT scanning equipment, softcopy imaging [31] and expiratory images allowed the present authors to confidently identify areas of reduced lung attenuation as emphysematous.

A number of study limitations require highlighting. Since the present data are from a small observational pilot study, the findings cannot be extrapolated to all survivors of moderateto-severe BPD before larger population-based studies are completed. Although perinatal details were similar amongst those who participated and those who did not (table 1), the method of recruitment and relatively low participation rate does invite selection bias. Additionally, the outcomes described are likely to be specific for the 1980s birth cohort, since changes in perinatal care in the 1990s, particularly the introduction of surfactant and glucocorticoid treatment, may significantly alter future adult outcomes. Furthermore, the association between abnormal lung function, radiological emphysema and BPD in the present study was descriptive rather than quantitative, due to the possibility of selection bias, and so no comment can be made regarding the overall burden of lung disease.

The present study does, however, provide enough data to suggest that larger, controlled, population-based studies are urgently required to fully define and guide the management of adult lung disease associated with extreme preterm birth. The present data are the most extensive that link structural and functional outcomes in adult survivors of moderate and severe BPD. Other strengths include the prospective, populationbased nature of the study, the availability of accurate and complete perinatal data, and the uniformity in perinatal treatment protocols.

The poor correlation between perinatal data and the severity of radiological emphysema and lung function in adult survivors of $\mathrm{BPD}$ is intriguing. Although it could relate to the relatively small number of subjects sampled, two other studies also noted a lack of significant correlations between perinatal variables (birthweight and gestational age) and degree of airflow limitation in their cohorts of adolescents and young adults [15, 19]. Future larger studies will aim to identify modifiable perinatal factors that predict adult outcomes of BPD.

Overall, the present data suggest that a significant number of adult survivors of moderate and severe bronchopulmonary dysplasia may be left with residual functional and characteristic structural pulmonary abnormalities. Although the total burden of disease remains to be determined, bronchopulmonary dysplasia-associated adult lung disease is likely to be seen more frequently and this disease should be included in the differential diagnosis of young adults presenting with emphysema. Adult physicians will need to become increasingly prepared to enquire about the perinatal history, recognise lung disease potentially associated with prematurity, and offer smoking cessation advice and long-term follow-up to these cohorts of young adults as they move past maximum lung growth and into their late $20 \mathrm{~s}$ and $30 \mathrm{~s}$.

\section{REFERENCES}

1 Jobe AH, Bancalari E. Bronchopulmonary dysplasia. Am J Respir Crit Care Med 2001; 163: 1723-1729.

2 Eber E, Zach MS. Long term sequelae of bronchopulmonary dysplasia (chronic lung disease of infancy). Thorax 2001; 56: 317-323.

3 Tracy SK, Tracy MB, Dean J, Laws P, Sullivan E. Spontaneous preterm birth of liveborn infants in women at low risk in Australia over 10 years: a population-based study. BJOG 2007; 114: 731-735.

4 Kennedy JD. Lung function outcome in children of premature birth. J Paediatr Child Health 1999; 35: 516-521.

5 Furman L, Baley J, Borawski-Clark E, Aucott S, Hack M. Hospitalization as a measure of morbidity among very low birth weight infants with chronic lung disease. J Pediatr 1996; 128: 447-452.

6 Gross SJ, Iannuzzi DM, Kveselis DA, Anbar RD. Effect of preterm birth on pulmonary function at school age: a prospective controlled study. J Pediatr 1998; 133: 188-192.

7 Hakulinen AL, Heinonen K, Länsimies E, Kiekara O. Pulmonary function and respiratory morbidity in schoolage children born prematurely and ventilated for neonatal respiratory insufficiency. Pediatr Pulmonol 1990; 8: 226-232.

8 Kitchen WH, Olinsky A, Doyle LW, et al. Respiratory health and lung function in 8-year-old children of very low birth weight: a cohort study. Pediatrics 1992; 89: 1151-1158.

9 Parat S, Moriette G, Delaperche MF, Escourrou P, Denjean A, Gaultier C. Long-term pulmonary functional 
outcome of bronchopulmonary dysplasia and premature birth. Pediatr Pulmonol 1995; 20: 289-296.

10 Blayney M, Kerem E, Whyte H, O'Brodovich $\mathrm{H}$. Bronchopulmonary dysplasia: improvement in lung function between 7 and 10 years of age. J Pediatr 1991; 118: 201-206.

11 Doyle LW, Cheung MM, Ford GW, Olinsky A, Davis NM, Callanan C. Birth weight $<1501 \mathrm{~g}$ and respiratory health at age 14. Arch Dis Child 2001; 84: 40-44.

12 Doyle LW, Ford GW, Olinsky A, Knoches AM, Callanan C. Bronchopulmonary dysplasia and very low birthweight: lung function at 11 years of age. J Paediatr Child Health 1996; 32: 339-343.

13 Koumbourlis AC, Motoyama EK, Mutich RL, Mallory GB, Walczak SA, Fertal K. Longitudinal follow-up of lung function from childhood to adolescence in prematurely born patients with neonatal chronic lung disease. Pediatr Pulmonol 1996; 21: 28-34.

14 Aquino SL, Schechter MS, Chiles C, Ablin DS, Chipps B, Webb WR. High-resolution inspiratory and expiratory CT in older children and adults with bronchopulmonary dysplasia. AJR Am J Roentgenol 1999; 173: 963-967.

15 Northway WH Jr, Moss RB, Carlisle KB, et al. Late pulmonary sequelae of bronchopulmonary dysplasia. $N$ Engl J Med 1990; 323: 1793-1799.

16 Doyle LW, Olinsky A, Faber B, Callanan C. Adverse effects of smoking on respiratory function in young adults born weighing less than 1000 grams. Pediatrics 2003; 112: 565-569.

17 Halvorsen T, Skadberg BT, Eide GE, Røksund OD, Carlsen $\mathrm{KH}$, Bakke P. Pulmonary outcome in adolescents of extreme preterm birth: a regional cohort study. Acta Paediatr 2004; 93: 1294-1300.

18 Vrijlandt EJ, Gerritsen J, Boezen HM, Grevink RG, Duiverman EJ. Lung function and exercise capacity in young adults born prematurely. Am J Respir Crit Care Med 2006; 173: 890-896.

19 Doyle LW, Faber B, Callanan C, Freezer N, Ford GW, Davis NM. Bronchopulmonary dysplasia in very low birth weight subjects and lung function in late adolescence. Pediatrics 2006; 118: 108-113.

20 Aukland SM, Halvorsen T, Fosse KR, Daltveit AK, Rosendahl K. High-resolution CT of the chest in children and young adults who were born prematurely: findings in a population-based study. AJR Am J Roentgenol 2006; 187: 1012-1018.
21 Howling SJ, Northway WH Jr, Hansell DM, Moss RB, Ward S, Müller NL. Pulmonary sequelae of bronchopulmonary dysplasia survivors: high-resolution CT findings. AJR Am J Roentgenol 2000; 174: 1323-1326.

22 Knudson RJ, Lebowitz MD, Holberg CJ, Burrows B. Changes in the normal maximal expiratory flow-volume curve with growth and aging. Am Rev Respir Dis 1983; 127: 725-734.

23 Crapo RO, Morris AH, Clayton PD, Nixon CR. Lung volumes in healthy, nonsmoking adults. Bull Eur Physiopathol Respir 1982; 18: 419-425.

24 Cotes JE, Chinn DJ, Quanjer PH, Roca J, Yernault JC. Standardization of the measurement of transfer factor (diffusing capacity). Report Working Party Standardization of Lung Function Tests, European Community for Steel and Coal. Official Statement of the European Respiratory Society. Eur Respir J 1993; 6: Suppl. 16, 41-52.

25 Gevenois PA, de Maertelaer V, De Vuyst P, Zanen J, Yernault JC. Comparison of computed density and macroscopic morphometry in pulmonary emphysema. Am J Respir Crit Care Med 1995; 152: 653-657.

26 Gevenois PA, De Vuyst P, de Maertelaer V, et al. Comparison of computed density and microscopic morphometry in pulmonary emphysema. Am J Respir Crit Care Med 1996; 154: 187-192.

27 Parr DG, Stoel BC, Stolk J, Stockley RA. Validation of computed tomographic lung densitometry for monitoring emphysema in $\alpha_{1}$-antitrypsin deficiency. Thorax 2006; 61: 485-490.

28 Thébaud B, Abman SH. Bronchopulmonary dysplasia: where have all the vessels gone? Roles of angiogenic growth factors in chronic lung disease. Am J Respir Crit Care Med 2007; 175: 978-985.

29 Walther FJ, Benders MJ, Leighton JO. Persistent pulmonary hypertension in premature neonates with severe respiratory distress syndrome. Pediatrics 1992; 90: 899-904.

30 Griscom NT, Wheeler WB, Sweezey NB, Kim YC, Lindsey JC, Wohl ME. Bronchopulmonary dysplasia: radiographic appearance in middle childhood. Radiology 1989; 171: 811-814.

31 Reiner BI, Siegel EL, Hooper FJ. Accuracy of interpretation of CT scans: comparing PACS monitor displays and hardcopy images. AJR Am J Roentgenol 2002; 179: 1407-1410. 